\title{
Primal and Dual Economic Measures of Capacity Utilization in Tunisia
}

\author{
Kamel Helali ${ }^{1}$, Mohamed Siala ${ }^{1} \&$ Maha Kalai ${ }^{1}$ \\ ${ }^{1}$ Department of Applied Quantitative Methods, Faculty of Economics and Management of Sfax, University of \\ Sfax, Tunisa \\ Correspondence: Kamel Helali, Department of Applied Quantitative Methods, Faculty of Economics and \\ Management of Sfax, University of Sfax, Tunisa. E-mail: helali.kamel@gmail.com
}

Received: March 14, 2013

Accepted: June13, $2013 \quad$ Online Published: June 25, 2013

doi:10.5539/ijef.v5n7p145

URL: http://dx.doi.org/10.5539/ijef.v5n7p145

\begin{abstract}
The primal and dual measures of capacity utilization under certain conditions, such as the nature of the economy of scale, have been widely used to analyze the current state of the economy in explaining the labor productivity and the inflation rate. However, the characteristics of certain measures are the ad hoc, since they are not based on explicit theoretical foundations. Nevertheless, many approaches have used the economic theory of cost and production by defining production capacity as the level of the output where the short and long run average total cost curves are tangent. Under the condition of constant returns to scale in the long run, productive capacity corresponds to the output that minimizes the short-run average total cost curve. To explain the shift of the aggregate production to industrial production, a dynamic duality theory has prompted researchers to revise the concept of the short-run production capacity, conditioned by a quasi-fixed stock of capital.
\end{abstract}

Keywords: capacity utilization, economic performance, total factor productivity, elasticity

\section{Introduction}

There is a general agreement of all the economists that production capacity $(P C)$ is a measure of the output. It is a potential production which must be equal to the maximum output or the economic output given the capital stock, the full use of variable production factors (energy, work, and materials), and technical efficiency. The two basic concepts of capacity discussed in economic literature are as follows: (1) a (Primal) technological concept, and (2) a (Dual) economic concept. For the economic approach, two different definitions of production capacity have been put in. The first, which was proposed by Klein (1960) and Friedman (1963), corresponds to output $Y_{t}$ where the short run (SRATC) and the long run (LRATC) average total cost curves are tangent. The second, which was recommended by Cassels (1937) and Hickman (1964), corresponds to output $Y_{m}$ where the short run average total cost curve reaches its minimum. This point of tangency at the minimum of the short run average total cost is also the point of efficient performance.

Two primal economic measures of capacity utilization $(C U)$ are shown in literature, $C U_{t}=Y / Y_{t}$ and $C U_{m}=Y / Y_{m}$. The relationship between the economic measures of the $C U$ depends on the degree of the economy of scale of the firm in question. Thus, under the condition of constant returns to scale, both definitions are equivalent. In the case where the returns to scale increase, we have $Y_{m}>Y_{t}$, which means that $C U_{m}<C U_{t}$. When there are decreasing returns to scale, $Y_{m}<Y_{t}$, which implies that $C U_{m}>C U_{t}$. The choice of a particular measure of the $C U$ is the consequence of a high correlation between the various measures, and the attempt to know whether this correlation is constant or not through time.

Regarding the dual economic measure of the $C U$, it should be noted that this measure was developed to investigate the case of a multi-product, (Segerson and Squires, 1990). Morrison (1985) provided the first starting point from the dual analysis of the $C U$ for a single product. The Dual $C U$, marked $C U$-cost or " $C U_{D}$ ", is defined as the ratio $C^{*}$ to $C$ where $C^{*}$ is the capital shadow cost noted by $Z_{K}$, and $C$ is the current total cost of production. When the firm is in a long-run equilibrium, the shadow value of capital $Z_{K}$ is equal to the actual cost of capital use $p_{K}$.If $C U_{D}>1$, this implies that $Z_{K}>p_{K}$ and there is an intention to invest, while if $T U C P_{D}<1$, this means that $Z_{K}<p_{K}$ and the firm prefers to divest. 
This article has three objectives. The first is to draw a portrait to estimate the $C U$ using the economic theory concepts. Although this estimate is based on a non-static temporary equilibrium (dynamic) specification, we use the Translog short-run variable cost function with constant returns to scale. This specification helps us to estimate the primal and dual $C U$. The second objective is to use these estimates to analyze the production growth and the productivity growth during the historical period through the estimation of the short and long run elasticities. The third objective is to estimate the effect of the changes in the $C U$ on the measurement of total factor productivity $(T F P)$ which also allows us to estimate the short and long run primal and dual effects on the evolution of the production capacity.

\section{Methodology}

\subsection{Specification of the Translog Cost Function}

The Translog function, which was introduced by Christensen and al. (1973), is an important development in the theory of production and its application. The following theory of the cost function has been fully exploited in studies and techniques to estimate the Allen partial substitution elasticities which have been widely used to determine the empirical nature of the application factors, (Chung, 1987). Therefore, we consider the Translog short-run variable cost function with capital quasi-fixed factor (Somayeh and al., 2012).

Let the variable inputs be, $L$, labor and, $E$, energy, and denote their respective price $p_{L}$ and $p_{E}$. We also note the level of output $Y$, capital stock $K$, and the effect of the technical progress by a trend component denoted $t$. Thus, the variable cost is defined as $V T C=p_{L} L+p_{E} E$. The Translog short-run variable cost function with constant returns to scale $(C R S)$ can be written as:

$$
\begin{aligned}
\operatorname{LnVTC} & =\alpha_{0}+\alpha_{t} t+\frac{1}{2} \alpha_{t t} t^{2}+\sum_{i=L, E} \alpha_{i} \operatorname{Ln} p_{i}+\beta_{Y} \operatorname{Ln} Y+\beta_{K} \operatorname{Ln} K+\frac{1}{2} \sum_{i=L, E} \sum_{j=L, E} \gamma_{i j} \operatorname{Ln} p_{i} \operatorname{Ln} p_{j} \\
& +\frac{1}{2} \gamma_{Y Y}[\operatorname{Ln} Y]^{2}+\frac{1}{2} \gamma_{K K}[\operatorname{Ln} K]^{2}+\frac{1}{2} \gamma_{\dot{K} \dot{K}}[\operatorname{Ln} \dot{K}]^{2}+\sum_{i=L, E} \rho_{Y i} \operatorname{Ln} Y \operatorname{Ln} p_{i}+\sum_{i=L, E} \rho_{K i} \operatorname{Ln} K \operatorname{Ln} p_{i} \\
& +\rho_{Y K} \operatorname{Ln} Y \operatorname{Ln} K+\rho_{Y \dot{K}} \operatorname{Ln} Y \operatorname{Ln} \dot{K}+\rho_{t Y} t \operatorname{Ln} Y+\rho_{t K} \operatorname{Ln} K+\sum_{i=L, E} \rho_{t i} \operatorname{Ln} p_{i}
\end{aligned}
$$

It should be noted that this function is a dynamic specification determined from the work of Berndt and Morrison (1981) and Diewert and Morrison (1987). It depends on the introduction of $\dot{K}$ that represents the change in the capital stock. In fact,

$$
\dot{K}_{t}=K_{t}-K_{t-1}=\Delta K_{t}
$$

where $\dot{K}$ plays the role of investment that incorporates the adjustment costs. This variable can be equal to:

$$
\dot{K}_{t}=r K_{t}
$$

where $r$ is the interest rate.

To ensure that the Translog short run variable cost function satisfies the curvature conditions, it must be homogeneous of degree 1 with respect to variable input prices, by knowing the given levels of $K, Y$ and $t$. The verification of this restriction determines the following restrictions:

$$
\alpha_{L}+\alpha_{E}=1 ; \gamma_{L L}+\gamma_{L E}=0 ; \gamma_{E E}+\gamma_{L E}=0 ; \rho_{Y L}+\rho_{Y E}=0 ; \rho_{K L}+\rho_{K E}=0 ; \rho_{t L}+\rho_{t E}=0
$$

As noted by Brown and Christensen (1981) and Berndt and Hesse (1986), the necessary and sufficient conditions to impose long-run CRS are

$$
\begin{gathered}
\beta_{Y}+\beta_{K}=1 ; \gamma_{Y Y}+\rho_{Y K}+\rho_{Y \dot{K}}=0 ; \gamma_{K K}+\rho_{Y K}=0 ; \\
\gamma_{\dot{K} \dot{K}}+\rho_{Y \dot{K}}=0 ; \rho_{Y L}+\rho_{K L}=0 ; \rho_{Y E}+\rho_{K E}=0 ; \rho_{t Y}+\rho_{t K}=0
\end{gathered}
$$

For empirical reasons, and based on the Shephard lemma, it is useful to use additional equations that reflect the behavior of optimization. The optimal demand equations (variable cost shares, $S_{i}$ ) are obtained by a logarithmic differentiation of the variable cost function over the logarithm of prices for variable inputs $p_{L}$ and $p_{E}$ knowing $K$, $Y$ and $t$. In fact,

$$
S_{i}=\frac{\partial \operatorname{LnVTC}}{\partial \operatorname{Ln} p_{i}}=\frac{\partial V T C}{\partial p_{i}} \frac{p_{i}}{V T C}=\frac{p_{i} X_{i}}{V T C}=\alpha_{i}+\gamma_{i i} \operatorname{Ln} p_{i}+\gamma_{i j} \operatorname{Ln} p_{j}+\rho_{Y i} \operatorname{Ln} Y+\rho_{K i} \operatorname{Ln} K+\rho_{t i} t
$$


In the above equations, the estimation is based on the quantitative level of capital $(\operatorname{Ln} K)$ instead of the price of capital $\left(\operatorname{Ln} p_{K}\right)$. However, the only existing important difference is that with a variable cost function, we can calculate the shadow cost (Shadow Price) of the quasi-fixed input and compare it with its operating cost. More specifically, the fictive value is the reduction in the variable cost by adding a unit of $K$. The fictive value denoted by $R_{K}$ is defined by:

$$
R_{K}=\frac{\partial V T C}{\partial K}<0
$$

If we apply a logarithmic differentiation to the Translog variable cost compared to the change of the capital, we obtain a logarithmic version of the fictive value. Let $S_{K}$ be the fictive share of the capital in the cost, we will have:

$$
S_{K}=\frac{\partial \operatorname{LnVTC}}{\partial \operatorname{Ln} K}=\frac{\partial V T C}{\partial K} \frac{K}{V T C}=\frac{R_{K} K}{V T C}=\beta_{K}+\gamma_{K L} \operatorname{Ln} p_{L}+\gamma_{K E} \operatorname{Ln} p_{E}+\rho_{Y K} \operatorname{Ln} Y+\gamma_{K K} \operatorname{Ln} K+\rho_{t K} t
$$

It should be noted that the value of $R_{K}$ is endogenous and reflects the best possible condition of the achievement of the firm's objective if we know the constraints that it faces. In this context, it is useful to note that if we specify the production price of firm $(p)$ to the marginal cost $(M C)$, we will have:

$$
M C=\frac{\partial V T C}{\partial Y}=p
$$

Thus, the logarithmic differentiation of the cost function due to the change of $Y$ and its price $p$ leads to:

$$
S_{Y}=\frac{\partial \operatorname{LnVTC}}{\partial \operatorname{Ln} Y}=\frac{p Y}{V T C}=\beta_{Y}+\gamma_{Y L} \operatorname{Ln} p_{L}+\gamma_{Y E} \operatorname{Ln} p_{E}+\gamma_{Y Y} \operatorname{Ln} Y+\rho_{Y K} \operatorname{Ln} K+\rho_{Y K} \operatorname{Ln} \dot{K}+\rho_{t Y} t
$$

To characterize the dynamic behaviour of the function, we introduce the fictive value of the capital variation, $\dot{K}$, $R_{\dot{K}}$ expressing the variable cost reduction following the increase in the net investment of an additional unit capital, $R_{\dot{K}}=\partial V T C / \partial \dot{K}<0$ where we define the fictive part of the capital investment, In fact,

$$
S_{\dot{K}}=\frac{\partial \operatorname{LnVTC}}{\partial \operatorname{Ln} \dot{K}}=\frac{\partial V T C}{\partial \dot{K}} \frac{\dot{K}}{V T C}=\frac{R_{K} \dot{K}}{V T C}=\rho_{Y \dot{K}} \operatorname{Ln} Y+\gamma_{\dot{K} \dot{K}} \operatorname{Ln} K
$$

In fact, the specification of the Translog cost function satisfies the hypothesis of neutrality of the technical progress through the following restrictions:

$$
\rho_{t Y}=\rho_{t K}=\rho_{t L}=\rho_{t E}=0
$$

By imposing the restrictions found above on the Translog variable total cost function and the share equations, we have the system of equation (13).

$$
\left\{\begin{array}{r}
\operatorname{Ln}\left(\frac{V T C}{Y p_{L}}\right)=\alpha_{0}+\alpha_{t} t+\frac{1}{2} \gamma_{t} t^{2}+\alpha_{E} \operatorname{Ln}\left(\frac{p_{E}}{p_{L}}\right)+\beta_{K} \operatorname{Ln}\left(\frac{K}{Y}\right)+\frac{1}{2} \gamma_{E E}\left[\operatorname{Ln}\left(\frac{p_{E}}{p_{L}}\right)\right] \\
\quad+\frac{1}{2} \gamma_{K K}\left[\operatorname{Ln}\left(\frac{K}{Y}\right)\right]^{2}+\frac{1}{2} \gamma_{\dot{K} \dot{K}}\left[\operatorname{Ln}\left(\frac{\dot{K}}{Y}\right)\right]^{2}+\rho_{K E} \operatorname{Ln}\left(\frac{p_{E}}{p_{L}}\right) \operatorname{Ln}\left(\frac{K}{Y}\right) \\
S_{L}=\alpha_{L}+\gamma_{L E} \operatorname{Ln}\left(\frac{p_{E}}{p_{L}}\right)+\rho_{K L} \operatorname{Ln}\left(\frac{K}{Y}\right) \\
S_{E}=\alpha_{E}+\gamma_{E E} \operatorname{Ln}\left(\frac{p_{E}}{p_{L}}\right)+\rho_{K E} \operatorname{Ln}\left(\frac{K}{Y}\right) \\
S_{K}=\beta_{K}+\rho_{K E} \operatorname{Ln}\left(\frac{p_{E}}{p_{L}}\right)+\gamma_{K K} \operatorname{Ln}\left(\frac{K}{Y}\right) \\
S_{\dot{K}}=\gamma_{\dot{K} \dot{K}} \operatorname{Ln}\left(\frac{\dot{K}}{Y}\right) \\
S_{Y}=\beta_{Y}+\rho_{Y E} \operatorname{Ln}\left(\frac{p_{E}}{p_{L}}\right)+\rho_{Y K} \operatorname{Ln}\left(\frac{K}{Y}\right)+\rho_{Y \dot{K}} \operatorname{Ln}\left(\frac{\dot{K}}{Y}\right)
\end{array}\right.
$$


To resolve the problem of singularity, since $S_{L}+S_{E}=1$ and $S_{K}+S_{\dot{K}}+S_{Y}=1$, it is important to eliminate the two share equations $S_{L}$ and $S_{\dot{K}}$. This system of stacked equations will be estimated by the efficient iterative method of SURE under constraints of Zellner (1962). From the assumption of long-run CRS and $S_{K}+S_{\dot{K}}+S_{Y}=1$, we can calculate the shadow value of the quasi-fixed input $K$, as $R_{K} K+R_{\dot{K}} \dot{K}+p Y=C T V$, then

$$
R_{K} K+R_{\dot{K}} \dot{K}=V T C-p Y
$$

So, if we introduce the dynamic behaviour presented by the introduction of variable $K$, the long-run equilibrium will be determined by:

$$
p_{K} K=-\left(R_{K} K+R_{\dot{K}} \dot{K}\right)=-\left(S_{K}+S_{\dot{K}}\right) V T C
$$

When $p_{K}<\{>\}-\left(R_{K} K+R_{\dot{K}} \dot{K}\right) / K$, then the firm may increase \{decrease $\}$ its capital intensity. For production capacity $Y^{*}$ and capacity utilization $C U=Y / Y^{*}$, we first note that these two expressions are short run concepts to which we refer in the case where capital is fixed in the short run. Following the Marshallian tradition, Berndt and Hesse (1986) defined $S R A T C_{0}$ as the short run average total cost curve, which corresponds to a capital stock $K_{0}$, and $S R A T C_{1}$ the short run average total cost curve that corresponds to a capital stock $K_{1}$, where $K_{0}<K_{1}$. Under the condition of constant returns to scale in the long run, $S R A T C_{0}$ and $S R A T C_{1}$ reach their minimum values at the output levels $Y_{0}^{*}$ and $Y_{1}^{*}$ where they are tangent to the horizontal long run total average cost curve, LRATC (Figure 1).

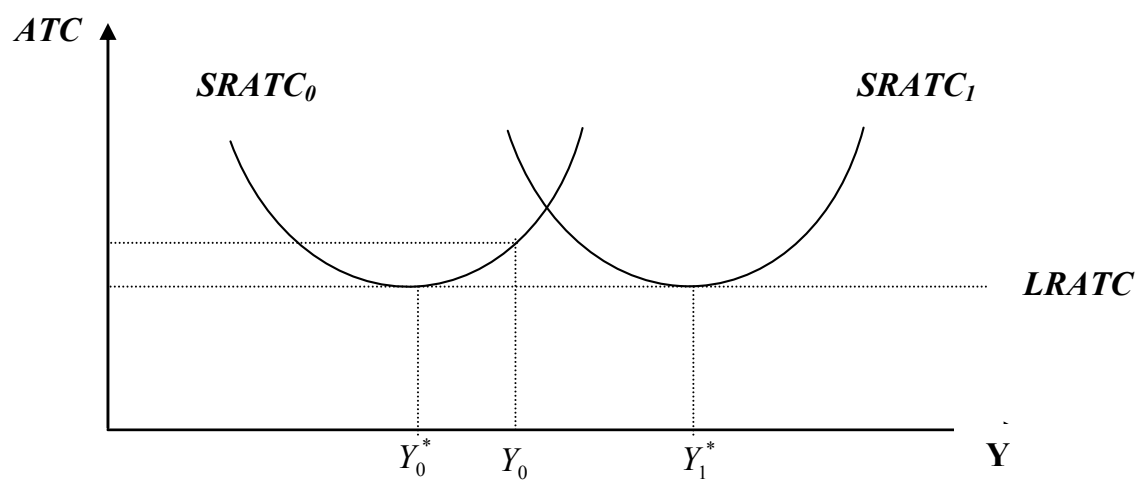

Figure 1. The short and long-run average total cost curves at CRS

An important finding that derived from the comments above is that the capacity utilisation ratio may be lower, higher, or equal to 1 . We also note that the $C U=1$ corresponds to an optimal output and capital stock. Thus, there is no incentive to change this stock. In addition, the condition that the following equality is checked, $p=M T C=A T C$, the $C U=1$ corresponds to a social optimum in which goods are produced and sold at the minimum average cost.

\subsection{Theoretical Determination of Primal and Dual Economic Capacity Utilization}

For the primal economic measures of production capacity, we have previously defined that the maximum output corresponds either to the minimum of the SRATC curve, $Y_{m}$, or to be the point of tangency of short and long run average total cost curves, $Y_{t}$.

First, we present the short run total cost as $T C_{S R}=V T C+F T C$ where $F T C$ is the fixed total cost equal to $F T C=p_{K} K$ with $p_{K}$ the cost of rental of a new capital. By dividing this total cost by output $Y$, the short run average total cost function is presented by $A T C=A V T C+A F T C . Y_{m}$ is the level of production that minimizes $S R A T C$, as well $\left(\partial S R T C / \partial Y_{\mid Y=Y_{m}}=0\right)$. For the Translog cost function this means that: 


$$
\left[\beta_{K}+\rho_{K E} \operatorname{Ln}\left(\frac{p_{E}}{p_{L}}\right)+\gamma_{K K} \operatorname{Ln}\left(\frac{K}{Y_{m}}\right)+\gamma_{\dot{K} \dot{K}} \operatorname{Ln}\left(\frac{\dot{K}}{Y_{m}}\right)\right] V T C=-p_{K} K
$$

It is clear that equation (16) depends on $\operatorname{Ln} Y_{m}$, making the analytical estimate of $Y_{m}$ difficult to minimize the $S R A T C$ function. Thus, it is necessary to employ a numerical iterative procedure to estimate the value of $Y_{m}$.

An alternative measure of the potential output proposed by Klein (1960) and Friedman (1963) corresponds to the point of tangency of the short and long run average total cost curves. This point is noted by $Y_{t}$. In terms of the Translog cost function, this implies:

$$
\frac{\partial S R T C}{\partial K^{*}}=\frac{\partial V T C}{\partial K^{*}}+p_{K}=Z_{K}+p_{K}
$$

where $Z_{K}=-\left(R_{K} K+R_{\dot{K}} \dot{K}\right) / K$ is the shadow value of the capital. This value represents the reduction of the variable cost by having a unit of $K$. For the CRS Translog cost function, this means that:

$$
\left[\beta_{K}+\rho_{K E} \operatorname{Ln}\left(\frac{p_{E}}{p_{L}}\right)+\gamma_{K K} \operatorname{Ln}\left(\frac{K}{Y_{m}}\right)+\gamma_{\dot{K} \dot{K}} \operatorname{Ln}\left(\frac{\dot{K}}{Y_{m}}\right)\right] V T C=-p_{K} K
$$

Thus, we justify that in the case where returns to scale are constant, there is an equality between the point of tangency of the short and long run average total cost curves and the minimum of the short run average total cost curve, $Y_{m}^{C R S}=Y_{t}^{C R S}$.

Let's turn now to the measure of the $C U$-Cost using previous theoretical developments. Indeed, we have $C U_{D}=\frac{V T C+Z_{K} K}{V T C+p_{K} K}=1+\left(Z_{K}-p_{K}\right) \frac{K}{C T}=1-\varepsilon_{C K}-\varepsilon_{C \dot{K}}$ where $\varepsilon_{C K}+\varepsilon_{C \dot{K}}=\left(p_{K}-Z_{K}\right) K / C T$. So, we have:

$$
C U_{D}=1-\left(p_{K}+\frac{R_{K} K+R_{\dot{K}} \dot{K}}{K}\right) \frac{K}{C T}=1-\frac{\left(S_{K}+S_{\dot{K}}\right) V T C+p_{K} K}{V T C+p_{K} K}
$$

\subsection{Calculation of the Short and Long Run Elasticities}

In the short run, it should be noted that the position of the short run average total cost curve depends on the levels of the factor prices and the amount of the capital. The change of $p_{i}$, for example, causes the movement of SRATC curve and so we can change its minimum point which determines the level of the production capacity noted $Y^{*}$. A very important calculation is summarized in the determination of the price elasticity of production noted $\varepsilon_{Y i}=\partial \operatorname{Ln} Y^{*} / \partial \operatorname{Ln} p_{i}$. The importance of this calculation is due to the fact that $Y^{*}$ cannot be resolved with a simple form, but must be numerically obtained by an iterative solution. In order to calculate the derivative of price elasticity of the production capacity, it is useful to use a procedure similar to the one used by Brown and Christensen (1981). Specifically, we evaluate the variable total cost, the shares of the variable inputs and the capital shadow share at the level of $Y=Y^{*}$ At the minimum point of SRATC curve, we have $A T C=\frac{V T C}{Y^{*}}+\frac{p_{K} K}{Y^{*}}=f\left(Y^{*}, p_{i}, K, \dot{K} ; t\right)$. So:

$$
\frac{\partial A T C}{\partial Y^{*}}=\frac{1}{Y^{*}} \frac{\partial V T C}{\partial Y^{*}}-\frac{V T C}{Y^{* 2}}-\frac{p_{K} K}{Y^{* 2}}=\frac{p Y^{*}-V T C}{Y^{*}}-\frac{p_{K} K}{Y^{* 2}}=0
$$

With the $C R S$, we have $S_{K}+S_{\dot{K}}+S_{Y}=1$ implying that:

$$
-\left(R_{K} K+R_{\dot{K}} \dot{K}\right)=p Y-V T C>0
$$

and as a result:

$$
p_{K} K=-\left(S_{K}+S_{\dot{K}}\right) V T C \equiv f_{Y}
$$

where $f_{Y}$ is the marginal variable cost. The total differential of $f_{Y}$ can be written as $d f_{Y}=\frac{\partial f_{Y}}{\partial Y^{*}} d Y^{*}+\sum_{i=L, E} \frac{\partial f_{Y}}{\partial p_{i}} d p_{i}+\frac{\partial f_{Y}}{\partial K} d K+\frac{\partial f_{Y}}{\partial \dot{K}} d \dot{K}+\frac{\partial f_{Y}}{\partial t} d t=0$, or $d p_{j(j \neq i)}=d K=d \dot{K}=d t=0$ Hence, we have $\frac{\partial f_{Y}}{\partial Y^{*}} \frac{d Y^{*}}{d p_{i}}+\frac{\partial f_{Y}}{\partial p_{i}}=0$, and after arrangement this gives us $\frac{d Y^{*}}{d p_{i}}=-\frac{\partial f_{Y}}{\partial p_{i}} / \frac{\partial f_{Y}}{\partial Y^{*}}$. For the short run Translog cost 
function this implies:

$$
\frac{d Y^{*}}{d p_{i}}=\left[\frac{\rho_{K i}+S_{i}\left(S_{K}+S_{\dot{K}}\right)}{\gamma_{K K}+\gamma_{\dot{K} K}+\left(S_{K}+S_{\dot{K}}\right)\left(S_{K}+S_{\dot{K}}-1\right)}\right] \frac{Y^{*}}{p_{i}}
$$

Thus, the elasticity of the production capacity, if we know the change in the input price, is defined:

$$
\varepsilon_{Y i}^{S R}=\frac{\partial \operatorname{Ln} Y^{*}}{\partial \operatorname{Ln} p_{i}}=\frac{d Y^{*}}{d p_{i}} \frac{p_{i}}{Y^{*}}=\frac{\rho_{K i}+S_{i}\left(S_{K}+S_{\dot{K}}\right)}{\gamma_{K K}+\gamma_{\dot{K} \dot{K}}+\left(S_{K}+S_{\dot{K}}\right)\left(S_{K}+S_{\dot{K}}-1\right)}
$$

This result is very important because it shows the substitutability/complementarity between the variable inputs and the capital since, similarly, $\varepsilon_{Y i}$ can check equality relating to the negative long run price elasticity between $K$ and $p_{i}$ :

$$
\varepsilon_{K i}^{L R}=\frac{\partial \operatorname{Ln} K}{\partial \operatorname{Ln} p_{i}}=-\varepsilon_{Y i}^{S R}
$$

In fact, if the variables input and capital are substitutes, then any increase in the price of input $i$ will lead to a reduction in the level of the production capacity. In other words, the increase in price $p_{i}$ increases the long run optimum ratio $K / Y$. In some cases, if we know the stock of capital $K$, the long run ratio $K / Y^{*}$ can be preserved by reducing the production capacity $Y^{*}$ operating at a new long run SRATC curve with the minimum point at the left of the initial level. Therefore, if the know $K$ and $Y$, an increase of $p_{i}$ reduces $Y^{*}$ and thus increases the $C U$ (Berndt and Hesse, 1986).

At the same time, and with reference to the work of Allen described by Chung (1987), we can estimate the elasticities of the substitution between the variable factors of production noted ESA (Elasticity of Substitution of Allen). We note, respectively, $\sigma_{i j}$ the cross-price elasticity or the elasticity of the demand for good $i$ following the change of the price of good $j$, and $\sigma_{i i}$ the direct price elasticity. Therefore, $\sigma_{i j}=\frac{\partial \operatorname{Ln} X_{i}}{\partial \operatorname{Ln} p_{j}}$ where $X_{i}=S_{i} V T C / p_{i}$, then:

$$
\sigma_{i j}^{S R}=\frac{\gamma_{i j}+S_{i} S_{j}}{S_{i}}
$$

For $\sigma_{i i}=\frac{\partial \operatorname{Ln} X_{i}}{\partial \operatorname{Ln} p_{i}}$, we will have:

$$
\sigma_{i i}^{S R}=\frac{\gamma_{i i}+S_{i}\left(S_{i}-1\right)}{S_{i}}
$$

In the long run, we will be in the standard case for measuring the elasticities of Allen: the level of production and the price of the fixed factors. At the equilibrium, we have, $p_{K} K=-\left(R_{K} K+R_{\dot{K}} \dot{K}\right)$. The variation of $K$ in the long run allows us to calculate $\partial K / \partial p_{K}$ where $p_{K}$ fits to $R_{K}+r R_{\dot{K}}$. Then $\partial K / \partial p_{K}=-\partial\left(R_{K}+r R_{\dot{K}}\right) / \partial K$, hence $\frac{\partial p_{K}}{\partial K}=-\left[\gamma_{K K}+\gamma_{\dot{K} \dot{K}}+S_{K}\left(S_{K}-1\right)+S_{\dot{K}}\left(S_{\dot{K}}-1\right)\right] \frac{V T C}{K^{2}}$. Let the impact of capital price change in relation to the capital be noted by:

$$
\varepsilon_{K K}^{L R}=\frac{\partial \operatorname{Ln} K}{\partial \operatorname{Ln} p_{K}}=-\frac{S_{K}+S_{\dot{K}}}{\gamma_{K K}+\gamma_{\dot{K} \dot{K}}+S_{K}\left(S_{K}-1\right)+S_{\dot{K}}\left(S_{\dot{K}}-1\right)}
$$

To calculate the long run cross elasticities due to the effect of the price input variations on capital inputs, noted $\varepsilon_{Y i}^{L R}$, it is interesting to show that the short run elasticity of the production prices $\varepsilon_{Y i}^{S R}$ in equation (21) can be equal to the negative long run price elasticity between $K$ and the input price $I$, hence we can write $\varepsilon_{K i}^{L R}=\frac{\partial \operatorname{Ln} K}{\partial \operatorname{Ln} p_{i}}=-\varepsilon_{Y i}^{S R}$.

Indeed, in the long run, we have $A T C=\frac{V T C}{Y^{*}}+\frac{p_{K} K}{Y^{*}}=f\left(Y^{*}, p_{i}, K, \dot{K} ; t\right) \quad \cdot \quad$ Therefore 
$\frac{\partial V T C}{\partial K^{*}}=-Z_{K}=\frac{R_{K} K+R_{\dot{K}} \dot{K}}{K}=R_{K}+r R_{\dot{K}}=\left(\frac{S_{K}}{K}+r \frac{S_{\dot{K}}}{\dot{K}}\right) V T C$. So, we get $\left(\frac{S_{K}}{K}+r \frac{S_{\dot{K}}}{\dot{K}}\right) V T C+p_{K}=0 \equiv f_{K}$ where $f_{K}$ is the capital marginal cost. The total cost differential can be written as $d f_{K}=\frac{\partial f_{K}}{\partial Y^{*}} d Y^{*}+\sum_{i=L, E} \frac{\partial f_{K}}{\partial p_{i}} d p_{i}+\frac{\partial f_{K}}{\partial K} d K+\frac{\partial f_{K}}{\partial \dot{K}} d \dot{K}+\frac{\partial f_{K}}{\partial t} d t=0$. But at $C R S$, we have $d p_{j(j \neq i)}=d Y^{*}=d t=0$. Hence, we will have $\frac{\partial f_{K}}{\partial K} \frac{d K}{d p_{i}}+\frac{\partial f_{K}}{\partial p_{i}}=0$. Then, after arrangement this gives $\frac{d K}{d p_{i}}=-\frac{\partial f_{K}}{\partial p_{i}} / \frac{\partial f_{K}}{\partial K}$. For the short run Translog cost function this implies:

$$
\frac{d K}{d p_{i}}=-\left[\frac{\rho_{K i}+S_{i}\left(S_{K}+S_{\dot{K}}\right)}{\gamma_{K K}+\gamma_{\dot{K} \dot{K}}+\left(S_{K}+S_{\dot{K}}\right)\left(S_{K}+S_{\dot{K}}-1\right)}\right] \frac{K}{p_{i}}
$$

Thus, the elasticity of the capital due to the change in input price $i$ is defined by:

$$
\varepsilon_{K i}^{L R}=-\frac{\rho_{K i}+S_{i}\left(S_{K}+S_{\dot{K}}\right)}{\gamma_{K K}+\gamma_{\dot{K} \dot{K}}+\left(S_{K}+S_{\dot{K}}\right)\left(S_{K}+S_{\dot{K}}-1\right)}=-\varepsilon_{Y i}^{S R}
$$

Beyond that, if for example, energy and capital are substitutable in the long run, then $\varepsilon_{K E}^{L R}<0$, thus the increase in the energy price causes a reduction in the production capacity level. Similarly, the increase in $p_{E}$ causes an increase in the capital average productivity ratio $\left(K / Y^{*}\right)$. Let's turn now to the long-run price cross-elasticity of the changes in the level of factor $i$ based on the capital price noted $\varepsilon_{i K}^{L R}$. We have $\partial X_{i} / \partial p_{K}=\partial X_{i} / \partial K^{*} \partial K / \partial p_{K}$. Therefore,

$$
\varepsilon_{i K}^{L R}=\frac{\partial \operatorname{Ln} X_{i}}{\partial \operatorname{Ln} p_{K}}=-\frac{\left\lfloor\rho_{K i}+S_{i}\left(S_{K}+S_{\dot{K}}\right)\right]\left(S_{K}+S_{\dot{K}}\right)}{\sqrt{\left.\gamma_{K K}+\gamma_{\dot{K} \dot{K}}+S_{K}\left(S_{K}-1\right)+S_{\dot{K}}\left(S_{\dot{K}}-1\right)\right] S_{i}}}
$$

We note that if the labour and capital are complementary, $\varepsilon_{L K}^{L R}$ is positive, thus, the increase in the capital price increases work as well as energy. Under the conditions of the constant returns to scale in the long run and $S_{K}+S_{\dot{K}}+S_{Y}=1$, we can conclude that $\varepsilon_{i Y^{*}}^{L R}+\varepsilon_{i K^{*}}^{L R}=1$. Thus, the effect of the variation of production on the input demand is defined by:

$$
\varepsilon_{i Y}^{L R}=1+\frac{\left.\rho_{K i}+S_{i}\left(S_{K}+S_{\dot{K}}\right)\right]\left(S_{K}+S_{\dot{K}}\right)}{\sqrt{\left.\gamma_{K K}+\gamma_{\dot{K} \dot{K}}+S_{K}\left(S_{K}-1\right)+S_{\dot{K}}\left(S_{\dot{K}}-1\right)\right] S_{i}}}
$$

\subsection{Measurement of Total Factor Productivity and Relationship with the Capacity Utilization}

The increasing measures of multifactor productivity have been long linked to external changes in the isoquants of production or downward changes in the average cost curves. Typically, such bonds are built on production and structure optimization assuming that all inputs are instantly adjustable. Thus, we assume that there is no distinction between the short and the long run. However, this distinction is very important, especially when large shocks occur. For such a case, and as a response to this adjustment, the characteristics of the behaviour of the company in the short run may differ materially from those that will take place once the long-run when equilibrium is reached. This part targets the estimate of the TFP following the increase in the marginal cost of the quasi-fixed factors, and therefore we need to distinguish between the short and long run sudden impacts.

The concept of TFP growth can be illustrated by Figure 2 . Let $L R A T C_{0}$ be the original average total cost curve, and a new curve of $L R A T C$ reflecting a technological state $L R A T C_{l}$. Under the assumption that the input prices are constant between, 0 and 1 , the envelope effect of technical progress is to reduce the unit cost from $c_{0}^{0}$ to $c_{1}^{0}$. Under the effect of the technical progress, the long run competitive equilibrium moves from $Y_{0}^{0}$ to $Y_{1}^{0}$. Thus, TFP can be calculated by leaving the quantities of inputs unchanged between periods 0 and 1 . Beyond that, the total cost must remain constant until the unit costs decline and the TFP growth can be measured as the logarithm of the ratio $Y_{1}^{0} / Y_{0}^{0}$ or, alternatively, by the logarithm of the ratio $c_{0}^{0} / c_{1}^{0}$.

This traditional TFP growth measurement is based on the assumption that in both periods $t_{0}$ and $t_{l}$, the current output equals the production capacity, i.e. $C U=1$, and all the observed points correspond to the economic production capacity levels and the minimum of the short run average total cost curve to know the couples $\left(c_{0}^{0}\right.$, 
$\left.Y_{0}^{0}\right)$ et $\left(c_{1}^{0}, Y_{1}^{0}\right)$. Moreover, an interpretation of the $T F P$ growth is necessary where the $C U$ is different from 1.

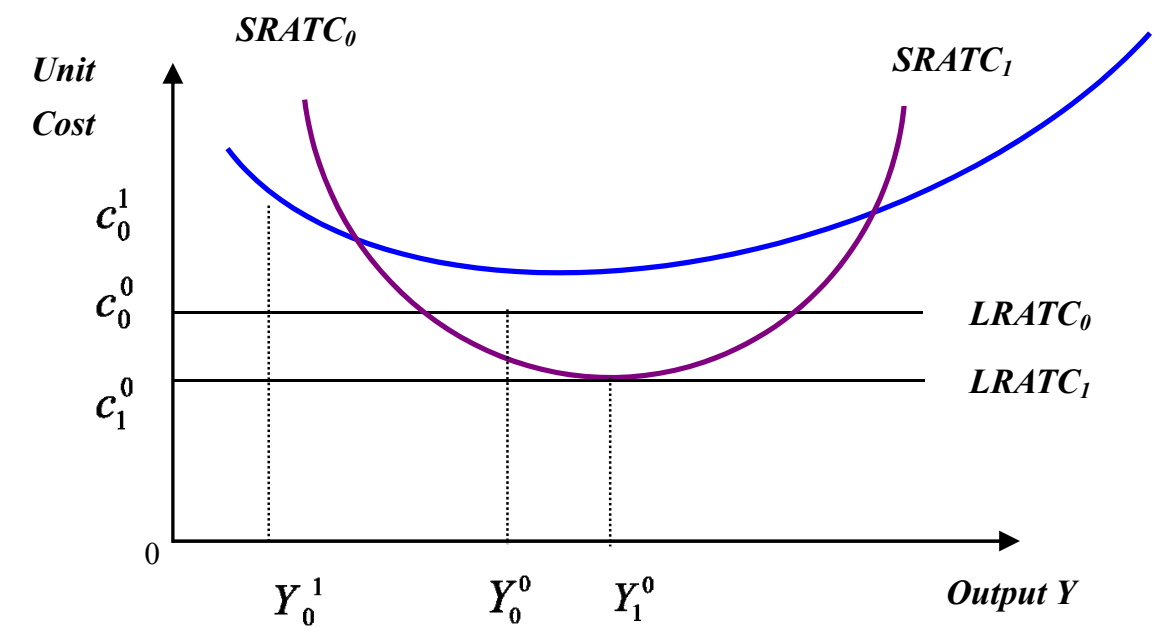

Figure 2. Relationship between TFP and CU

In Figure 2, let $Y_{0}^{1}$ be the optimal level $Y_{0}^{1}$ instead of $Y_{0}^{1}$. As $Y_{0}^{1}<Y_{0}^{0}$, the original capacity utilization is $C U_{0}<1$. Let the level of output in the period 1 be $Y_{1}^{0}$, this implies that as long as $C U_{0}<1, C U_{1}=1$. Let's suppose that the input prices do not change between periods 0 and 1. If points $\left(c_{0}^{1}, Y_{0}^{1}\right)$ and $\left(c_{1}^{0} Y_{1}^{0},\right)$ are observable, it is incorrectly assumed that they represent the long-run equilibrium, $C U=1$, and if the TFP growth is measured, the real growth of the TFP will be underestimated.

With $C R S$, and if we have a single quasi-fixed input capital $K$ and two variable inputs labor $L$ and energy $E$, the primal measure of the total factor productivity growth $\left(\varepsilon_{Y t}^{S R}\right)$ compatible with the short run is defined by:

$$
\varepsilon_{Y t}^{S R}=\frac{\dot{Y}}{Y}-\left(\hat{S}_{L} \frac{\dot{L}}{L}+\hat{S}_{E} \frac{\dot{E}}{E}+\hat{S}_{K} \frac{\dot{K}}{K}+\hat{S}_{\dot{K}} \frac{\ddot{K}}{\dot{K}}\right)
$$

Similarly, we define the long-run primal measure noted $\varepsilon_{Y t}^{L R}$, such as

$$
\varepsilon_{Y t}^{L R}=\frac{\dot{Y}}{Y}-\frac{1}{1-\varepsilon_{C K}-\varepsilon_{C \dot{K}}}\left(\hat{S}_{L} \frac{\dot{L}}{L}+\hat{S}_{E} \frac{\dot{E}}{E}+\hat{S}_{K} \frac{\dot{K}}{K}+\hat{S}_{\dot{K}} \frac{\ddot{K}}{\dot{K}}\right)
$$

where $1-\varepsilon_{C K}-\varepsilon_{C K}$ serves as the dual measure of $C U$ or the $C U$-Cost.

The dual measure of the TFP growth $\left(\varepsilon_{C t}^{S R}\right)$ under the assumption of temporary equilibrium is the difference between the growth rate of output price and the price of the aggregate inputs.

$$
\varepsilon_{C t}^{S R}=\left(1-\varepsilon_{\mathrm{CK}}-\varepsilon_{\mathrm{CK}}\right) \frac{\dot{Y}}{Y}-\left(\hat{S}_{L} \frac{\dot{L}}{L}+\hat{S}_{E} \frac{\dot{E}}{E}+\hat{S}_{K} \frac{\dot{K}}{K}+\hat{S}_{\dot{K}} \frac{\ddot{K}}{\dot{K}}\right)
$$

It is possible, however, to introduce the real impact of technical progress $\varepsilon_{C t}^{L R}$ as the product of both parts: the effect of the observed production and the effect of short run rigidity or of the under-balanced:

$$
\varepsilon_{C t}^{L R}=\frac{\dot{Y}}{Y}-\frac{1}{1-\varepsilon_{C K}-\varepsilon_{C \dot{K}}}\left(\hat{S}_{L} \frac{\dot{L}}{L}+\hat{S}_{E} \frac{\dot{E}}{E}+\hat{S}_{K} \frac{\dot{K}}{K}+\hat{S}_{\dot{K}} \frac{\ddot{K}}{\dot{K}}\right)=\varepsilon_{Y t}^{L R}
$$

In addition, we define so $\varepsilon_{C Y}=1-\varepsilon_{C K}-\varepsilon_{C \dot{K}}=C U_{D}$. In the long run, where the $C U=1$, we can verify that 
$\varepsilon_{C K}=\varepsilon_{C \dot{K}}=0$. Thus, we will have $\varepsilon_{C t}^{L R}=\varepsilon_{C t}^{S R}=\varepsilon_{Y t}^{L R}=\varepsilon_{Y t}^{S R}$. Indeed, we have:

$$
\varepsilon_{C t}^{L R}=\varepsilon_{Y t}^{L R}=\frac{\varepsilon_{C t}^{S R}}{1-\varepsilon_{C K}-\varepsilon_{C \dot{K}}}=\frac{\varepsilon_{Y t}^{S R}}{1-\varepsilon_{C K}-\varepsilon_{C \dot{K}}}
$$

\section{Empirical Analysis}

Development in the theory of duality allows researchers to estimate the production capacity and the capacity utilization rate with functional forms of the cost. Generally, we use the "Seemingly Unrelated Regressions" (SURE) or even the system of stacked equation used with panel data. The cost function accommodates the industry-specific variability through a composed error model. Sector-specific effects, which are supposed to be fixed, mean that the differences across the sectors can be captured in the differences in the constant term. In fact, the benefits of using Panel data are diverse. In these regressions, several models can be built in the occurrence of an error-correction model to justify the structure of the error terms.

\subsection{Data Descriptions}

The data used in this study cover the Tunisian manufacturing sectors observed during the 1970-2006 period. Individual industries included in the data set are Agriculture \& Food Industries (AFI), Building Materials, Ceramics \& Glass $(B C C G)$, Mechanical \& Electrical Industries (MEI), Chemical Industries $(C H I)$, Textiles, Clothing \& Leather $(T C L)$ and Various Manufacturing Industries $(V M I)$. The data set contains 222 observations of Tunisian manufacturing data. The number of periods $(T=37)$, which exceeds that sectors $(N=6)$, allows us to use the SURE model to estimate the average variable cost functions and share equations. The data are obtained from the Tunisian Institute of Competitiveness and Quantitative Studies (TICQS). The used data include: the production quantity $(Y)$, the labour quantity $(L)$, the stock of capital at the beginning of each period $(K)$, the capital investment represented by the Gross Fixed Capital Formation $\left(\dot{K}=I_{K}\right)$, the energy cost $(E V)$, the average annual salary $\left(p_{L}\right)$, the payroll will $(W B)$, the user cost of capital $\left(p_{K}\right)$, and the energy price $\left(p_{E}\right)$.

Before proceeding to the empirical results, there is a number of debatable subjects related to the estimation of this system. Firstly, this model is based on the assumption of stationarity of all the variables in the regression. Therefore, we will move to the unit root statistic tests on Panel data of first and second generation of the generated variables of the reduced form. Then, testing the presence of the unit roots in our panel data, we will retain a first difference specification comparable to the one used in time series studies.

\subsection{The Unit Root Test}

In this part, we applied a number of tests of first and second-generation in panel data. The applied tests are: Levin, Lin and Chu (2002), Im, Pearson and Shin (2003) Maddala and Wu (1999), Hadri (2000), Bai and Ng (2004), Moon and Perron (2004), Choi (2002), Pesaran (2007) and Chang (2002). It follows, from these tests, that the majority of the variables failed to pass the various statistics at confidence level of $95 \%$. In addition, to study the sensitivity of the results found, we consider the individual pooled ADF statistics for each variable in order to compare the ADF statistics developed by Bai and $\mathrm{Ng}$ (2004). For variable $L V C Y L$, we find Table 1.

Table 1. Comparison of ADF statistics for the six sectors

\begin{tabular}{llll}
\hline Sectors & ADF & CADF & IV ADF \\
\hline$A F I$ & -1.81 & -0.16 & 0.29 \\
& $(0.68)$ & $(0.99)$ & $(0.61)$ \\
$B C C G$ & -1.39 & -2.67 & -0.66 \\
& $(0.84)$ & $(0.33)$ & $(0.25)$ \\
$M E I$ & -4.69 & -0.91 & 0.48 \\
& $(0.01)$ & $(0.94)$ & $(0.69)$ \\
CHI & -1.57 & -2.69 & 1.44 \\
& $(0.79)$ & $(0.33)$ & $(0.93)$ \\
$T C L$ & -2.02 & -0.48 & -0.61 \\
& $(0.57)$ & $(0.98)$ & $(0.27)$ \\
& -7.62 & -2.14 & -0.62 \\
\end{tabular}

Notes: Individual ADF statistics, CADF (Pesaran, 2003) and nonlinear IV ADF (Chang, 2002) are reported for each sector for each variable. The corresponding p-values are in brackets. 
For the $A D F$ tests, sectors $A F I, B C C G, C H I$ and $T C L$ reject the null hypothesis despite the non-stationarity of the idiosyncratic component. If we compare this result with that of the $C A D F$ statistics, we will find a different result. For all the sectors, we do not reject the null hypothesis of variable LVCYL. Therefore, if we consider the common factor in LVCYL sector manufacturing, by introducing increased terms across sections, the non-stationarity will be widely accepted.

Table 2. Order of integration of model variables

\begin{tabular}{llllllllllll}
\hline TEST & LVCYL & LEL & LEL2 & LKY & LKY2 & LKYEL & LDKY & LDKY2 & SE & SK & SY \\
\hline LLC (2002) & 0 & 1 & 1 & 1 & 1 & 1 & 1 & 1 & 1 & 1 & 1 \\
IPS (2003) & 0 & 1 & 0 & 1 & 1 & 1 & 1 & 0 & 1 & 1 & 1 \\
$M \& W(1999)$ & 0 & 1 & 0 & 1 & 1 & 1 & 1 & 0 & 1 & 1 & 1 \\
Hadri (2000) & 1 & 1 & 1 & 1 & 1 & 1 & 1 & 1 & 1 & 1 & 1 \\
$B \& N(2004)$ & 1 & 1 & 0 & 1 & 0 & 1 & 0 & 1 & 0 & 1 & 1 \\
$M \& P(2004)$ & 1 & 0 & 0 & 1 & 1 & 0 & 1 & 0 & 0 & 1 & 1 \\
Choi (2002) & 1 & 1 & 0 & 1 & 1 & 1 & 0 & 0 & 1 & 1 & 1 \\
Pesaran (2007) & 1 & 1 & 1 & 1 & 1 & 1 & 1 & 1 & 1 & 1 & 1 \\
Chang (2002) & 1 & 1 & 1 & 1 & 1 & 1 & 1 & 1 & & 1 & 1 \\
\hline
\end{tabular}

In total, all the variables are integrated of order 1 with respect to the various tests, therefore we have summarized the order of integration in Table 2. Indeed, this table shows the non-stationarity of the variables in the CRSTranslog cost function model and its share equations, from which we have the transition to the first difference.

\subsection{Cointegration Tests}

For the equation of the CRS Translog cost function, Pedroni (1999) test shows that there is a cointegration relationship between the variable representing the average variable cost and the transformed variables of models LEL, LEL2, LKY, LKY2 and LDKY2. All the statistics of Pedroni (1999) reject the null hypothesis of no cointegration. Therefore, we can conclude that there is at least one cointegration relationship between the variables in the CRS Translog cost function equation.

Table 3. Test of cointegration of pedroni: LVCYL equation

\begin{tabular}{lll}
\hline Cointegration Tests & Value & p-values \\
\hline Panel Statistics (Non Para): $Z_{\hat{v}}^{W}$ & 4.40 & $0.3 \mathrm{e}^{-2}$ \\
Panel Statistics (Non Para): $Z_{\hat{\rho}}^{W}$ & -8.38 & $0.6 \mathrm{e}^{-3}$ \\
Panel Statistics (Non Para): $Z_{t}^{W}$ & -3.77 & $0.2 \mathrm{e}^{-3}$ \\
Panel $t$ Statistics (Para): $Z_{t}^{* W}$ & -71.2 & 0.00 \\
Group Statistics (Non Para): $\widetilde{Z}_{\hat{\rho}}^{B}$ & -10.95 & 0.00 \\
Group $t$ Statistics (Non Para): $\widetilde{Z}_{t}^{B}$ & -4.97 & $0.12 \mathrm{e}^{-3}$ \\
Group $t$ Statistics (Para): $\widetilde{Z}_{t}^{* B}$ & -5.78 & $0.5 \mathrm{e}^{-2}$
\end{tabular}

Notes: If the Panel statistic $v$ is greater than 1.6445, we accept the hypothesis of cointegration. For all other statistics are compared against -1.6445 .

Using the Kao (1999) tests, based on the OLS residuals, all the statistical tests, except the $D F_{\rho}$ which is based on the strict exogeneity assumption of the regressors, largely reject the null hypothesis of the absence of cointegration.

Table 4. Cointegration test of Kao: LVCYL equation

\begin{tabular}{lllllll}
\hline Statistics & $D F_{\rho}$ & $D F_{t}$ & $D F_{\rho}^{*}$ & $D F_{t}^{*}$ & ADF & Lag \\
\hline Valeur & -0.65 & -1.76 & -3.91 & -2.18 & -2.58 & 1 \\
$p$-value & 0.26 & 0.04 & 0.00 & 0.01 & $0.5 \mathrm{e}^{-2}$ & \\
\hline
\end{tabular}

Notes: The ADF is the ADF statistic based on the residuals of Kao (1999), we report the statistics estimated by one lag due to AIC $=-4.5929$ and $\mathrm{SBC}=4559$. 


\subsection{Hypothesis Testing}

At 5\%, Fisher statistics indicates a tabulated value of 2.21 . The large value of $\mathrm{F}$ statistics rejects the null hypothesis in favour of the fixed effect model.

Table 5. Fixed effect test

\begin{tabular}{lllllllll}
\hline Equations & LVCYL & & SE & & SK & & SY & \\
\hline Model & Stacked & LSDV & Stacked & LSDV & Stacked & LSDV & Stacked & LSDV \\
RSS & 17.22 & 10.72 & 2.45 & 0.66 & 94.51 & 56.4 & 93.76 & 56.4 \\
$d f$ & 215 & 210 & 219 & 214 & 219 & 214 & 218 & 213 \\
Statistic & $\mathrm{F}^{\mathrm{C}}=25.44$ & & $\mathrm{~F}^{\mathrm{C}}=115.08$ & $\mathrm{~F}^{\mathrm{C}}=28.92$ & & $\mathrm{~F}^{\mathrm{C}}=28.22$ & \\
\hline
\end{tabular}

The LM test of Breusch-Pagan is designated to test the random effect. At $5 \%$, we reject the null hypothesis in favour of the random effect model per group for all the equations. However, the null hypothesis of the random effect per period is accepted for the pooled model for both equations $L V C Y L$ and SE. For the double random effect model, the null hypothesis of having zero variances for individuals and periods is largely rejected at two degrees of freedom.

Table 6. Random effect test

\begin{tabular}{lllllllll}
\hline Equation & LVCVYL & & SE & & SK & & SY & \\
\hline Model & $L M^{T}$ & $L M^{T}$ & $L M^{I}$ & $L M^{T}$ & $L M^{I}$ & $L M^{T}$ & $L M^{I}$ & $L M^{T}$ \\
value & 308.9 & 0.23 & 1033.5 & 0.9 & 500.9 & 10.9 & 462.2 & 10.2 \\
p-values & 0.00 & 0.63 & 0.00 & 0.34 & 0.00 & 0.00 & 0.00 & 0.00 \\
Sum & 309.08 & & 1034.4 & & 511.91 & & 472.44 & \\
\hline
\end{tabular}

In fact, the four equations of the system show strong heterogeneity parameters. For the sample considered, the realization of the Hausman statistics test shows the rejection of the null hypothesis of no correlation between the individual effects and the explanatory variables. The transformed variables in the model are correlated with the structural and temporal features. Thus, we must emphasize here the adoption of a fixed effect model and retain the WITHIN estimator.

Table 7. Hausman homogeneity test

\begin{tabular}{|c|c|c|c|c|c|c|c|c|c|c|c|c|}
\hline \multirow[t]{2}{*}{ Equation } & \multicolumn{3}{|c|}{ LVCYL } & \multicolumn{3}{|l|}{ SE } & \multicolumn{3}{|l|}{ SK } & \multicolumn{3}{|l|}{ SY } \\
\hline & $F_{1}$ & $F_{2}$ & $F_{3}$ & $F_{1}$ & $F_{2}$ & $F_{3}$ & $F_{1}$ & $F_{2}$ & $F_{3}$ & $F_{1}$ & $F_{2}$ & $F_{3}$ \\
\hline value & 26.7 & 17.1 & 25.4 & 121.2 & 34.4 & 115.1 & 129.7 & 107.8 & 28.9 & 101.9 & 76.5 & 28.2 \\
\hline p-values & 0.00 & 0.00 & 0.00 & 0.00 & 0.00 & 0.00 & 0.00 & 0.00 & 0.00 & 0.00 & 0.00 & 0.00 \\
\hline$H$ & 7.42 & & & 7.75 & & & 2.25 & & & 5.78 & & \\
\hline p-values & 0.19 & & & 0.021 & & & 0.33 & & & 0.12 & & \\
\hline
\end{tabular}

Regardless the hypothesis considered about the nature of returns, Hausman tests indicate that, for all the studied sectors, the assumption of random effects cannot be rejected at $5 \%$ level in favour of the fixed effect hypothesis. We can also verify that the estimates carried out in the presence of fixed effects are relatively close to those carried out under the assumption of random effects, which proves that the bias related to a possible correlation seems relatively low.

Table 8. Poolabilty data test

\begin{tabular}{lllllllll}
\hline Equation & LVCYL & & $\mathrm{SE}$ & & $\mathrm{SK}$ & \multicolumn{3}{c}{$\mathrm{SY}$} \\
\hline Model & Stacked & Individual & Stacked & Individual & Stacked & Individual & Stacked & Individual \\
RSS & 17.22 & 2.78 & 2.45 & 0.25 & 94.51 & 8.97 & 93.76 & 8.31 \\
$d f$ & 215 & 180 & 219 & 204 & 219 & 204 & 218 & 198 \\
Statistic & $\mathrm{F}^{\mathrm{C}}=26.65$ & & $\mathrm{~F}^{\mathrm{C}}=121.2$ & & $\mathrm{~F}^{\mathrm{C}}=129.6$ & $\mathrm{~F}^{\mathrm{C}}=101.9$ \\
\hline
\end{tabular}

To verify the usefulness of the Panel data use, we move to the Chow test between a stacked model and the models individually tested. In fact, the null hypothesis consists of the sector homogeneity against the alternative one where sectors are heterogeneous. It should be noted that the stationarity of the series used is considered in 
this estimate. Thus, we test from the variables in first differences.

At 5\% level of significance, the large values found reject the null hypothesis of poolability. We conclude that the panel data are not poolable in relation to the different groups. In this case, we should consider a model with random coefficients and a hierarchical regression. The Durbin-Watson test, for serial correlation of the first order, and the LM test, for the presence of positive serial correlation in Panel data, are applied. The LM test statistics exceeds the critical value and the Durbin-Watson "DW" is lower than the low critical value showing the presence of a serial correlation in the model. These results are derived from the table below.

Table 9. Serial correlation test before correction

\begin{tabular}{lllll}
\hline CRSTL_Cost_Equation & Value & Asym. law & Crit. Val. & Decision \\
\hline LM Test (fixed effect) & 9.17 & $N(0,1)$ & 1.96 & $C S+$ \\
& $(0.00)$ & & & \\
LM Test (Joint) & 40.4 & $\chi_{2}^{2}$ & 5.99 & $C S+$ \\
& $(0.00)$ & & & \\
DW Test & 1.15 & & $d l=1.83 ; d u=1.88^{*}$ & $C S+$ \\
\hline
\end{tabular}

Notes: + CS represents the existence of a positive serial correlation. * Bhargava, Franzini and Narendranathan (1982).

To verify the homoscedasticity of the regression errors, we will apply the LM and the Wald tests transformed to a fixed effect model. At the significance level of $5 \%$, the large values found reject the null hypothesis of homoscedasticity. There is a wide heteroscedasticity of errors in the regression. Because of the great heterogeneity in the cross section, we calculate the values of Rho for each sector instead of the Rho of the panel. The major differences between the values of Rho confirm the difference in the degree of the individual's serial correlation.

Table 10. Heteroscedasticity test

\begin{tabular}{lllll}
\hline Equation & LVCYL & SE & SK & SY \\
\hline$L M$ & 114.6 & 1120.2 & 484.1 & 481.9 \\
$p$-values & 0.00 & 0.00 & 0.00 & 0.00 \\
\hline
\end{tabular}

After correcting the data using the individual values of Rho, we observe an improvement of the positive serial correlation from the LM test, but this test did not accept the null hypothesis of no serial correlation. However, the DW test, for first order serial correlation, did not reject the null hypothesis, which indicates that the problem of serial correlation no longer exists.

Table 11. Values of Rho by sector

\begin{tabular}{lllllll}
\hline Sectors & AFI & BCCG & MEI & CHI & TCL & VMI \\
\hline Rho & 0.91 & 0.80 & 0.49 & 0.42 & 0.85 & 0.51 \\
\hline
\end{tabular}

The problem of heteroscedasticity is accepted due to the nature of the sectors in question. Thus, we impose a structure on the White heteroscedasticity of error terms in the original model. A GLS specification was estimated where the cross-section heteroscedasticity and contemporaneous correlation were taken into account. From the results of the specification tests, a composite error model can be adjusted to different variables. Since the number of sectors is generally lower than the coefficients to estimate, a random effect model cannot be used. The fixed effect models (Within \& LSDV) are applied to the data. Thus, the system of equations formed by the Translog variable cost function and share equations are estimated by the iterative SURE technique.

Table 12. Serial correlation test after correction

\begin{tabular}{lllll}
\hline CRSTL_Cost_Equation & Value & Asym. law & Crit. Val. & Decision \\
\hline LM Test (Fixed effect) & 5.6 & $N(0,1)$ & 1.96 & $S C+$ \\
& $(0.00)$ & & & \\
LM Test (Joint) & 17.7 & $\chi_{2}^{2}$ & 5.99 & $S C+$ \\
& $(0.00)$ & & & No SC \\
DW Test & 2.06 & & $d l=1.83 ; d u=1.88$ & \\
\hline
\end{tabular}




\subsection{Estimates and Interpretations}

The final SURE iterative model, after correcting the serial correlation and heteroscedasticity adjustment, is summarized in Table 13.

After the correction of the serial problems, the estimates of the Translog cost function at constant returns to scale have shown the economic evidence. In fact, convexity with respect to $K$ and concavity with respect to the input prices $p_{i}$ are checked. The estimated coefficients have the expected signs, in particular $\hat{\gamma}_{K K}=0.82$, which justifies the effect of capital accumulation in the manufacturing sector. The non-significance of the ratio of energy prices is justified by the weak effect of the energy factor on the average variable cost. The effect of labor dominates energy. The effect of capital investments is not significant.

Table 13. Estimation of equation system of the CRS Translog cost function

\begin{tabular}{lllll}
\hline Coefficients & Variables & Standard Deviation & t_Stat. & p-values \\
\hline$\alpha_{0}$ AFI & 1.08 & 0.14 & 7.79 & 0.00 \\
$\alpha_{0}{ }_{-}$BCCG & 2.99 & 0.16 & 18.6 & 0.00 \\
$\alpha_{0}{ }^{\text {MEI }}$ & 1.77 & 0.15 & 11.9 & 0.00 \\
$\alpha_{0}{ }_{-}$CHI & 2.65 & 0.16 & 16.8 & 0.00 \\
$\alpha_{0-}$ TCL & 0.97 & 0.14 & 6.9 & 0.00 \\
$\alpha_{0-}$ VMI & 1.39 & 0.14 & 9.8 & 0.00 \\
$\alpha_{L}$ & 1.02 & 0.02 & 49.5 & 0.00 \\
$\alpha_{E}$ & -0.02 & 0.02 & -0.87 & 0.39 \\
$\beta_{Y}$ & 1.13 & 0.09 & 12.6 & 0.00 \\
$\beta_{K}$ & -2.13 & 0.09 & -24.1 & 0.00 \\
$\gamma_{L L}$ & 0.51 & 0.02 & 3.36 & 0.00 \\
$\gamma_{E E}$ & 0.51 & 0.02 & 3.36 & 0.00 \\
$\gamma_{L E}$ & -0.51 & 0.02 & -3.36 & 0.00 \\
$\gamma_{Y Y}$ & 0.82 & 0.06 & 14.53 & 0.00 \\
$\gamma_{K K}$ & 0.82 & 0.06 & 14.53 & 0.00 \\
$\gamma_{\dot{K} K}$ & $0.7 \mathrm{e}^{-4}$ & $0.5 \mathrm{e}^{-3}$ & 0.14 & 0.89 \\
$\rho_{Y K}$ & -0.82 & 0.06 & -14.53 & 0.00 \\
$\rho_{Y K}$ & $-0.7 \mathrm{e}^{-4}$ & $0.5 \mathrm{e}^{-3}$ & -0.14 & 0.89 \\
$\rho_{Y L}$ & 0.12 & 0.01 & 8.98 & 0.00 \\
$\rho_{Y E}$ & -0.12 & 0.01 & -8.98 & 0.00 \\
$\rho_{K L}$ & -0.12 & 0.01 & -8.98 & 0.00 \\
$\rho_{K E}$ & 0.12 & 0.01 & 8.98 & 0.00 \\
$\alpha_{t}$ & $0.8 \mathrm{e}^{-2}$ & 0.01 & 0.66 & 0.51 \\
$\gamma_{t t}$ & $-0.2 \mathrm{e}^{-2}$ & $0.6 \mathrm{e}^{-3}$ & -3.81 & 0.00 \\
\hline & & & &
\end{tabular}

The CU results, as a measure of efficiency of the Tunisian manufacturing sector, show values lower than the unity (Figure3). This means that there is an under-utilization of the production capacity during the study period (1970-2006). The dual measurement represents low rates reaching a value of $23.8 \%$. This can be explained by the high capital accumulation. Despite the wide dispersion between the estimated values, there is a strong positive correlation in their evolution. Both series move in almost in the same direction.

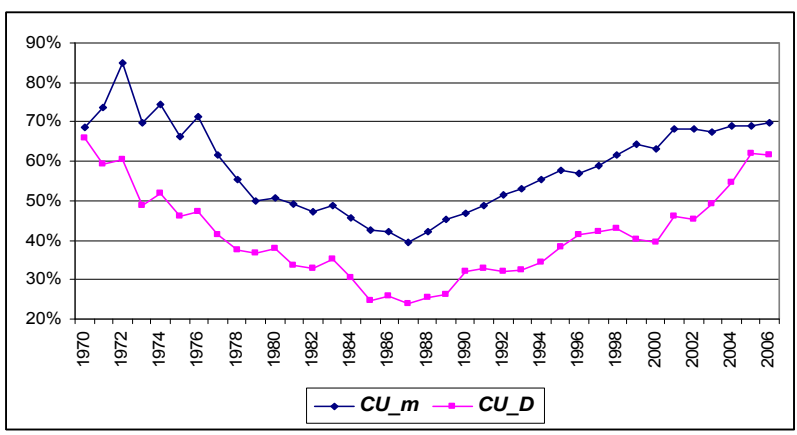

Figure 3. Evolution of the primal and the dual $\mathrm{CU}$ 
From the estimated results of the $C U$ at $C R S$ using the flexible form of the Translog cost function, we find an under-utilization of the production capacity in Tunisia, precisely in the manufacturing sector. This industrial inefficiency proved by this performance indicator is relatively logical to the available resources and the economic policy adopted by the country. The study of the productive performance of the Tunisian economy using the capacity utilization indicator showed that the economy has experienced an underutilization of capacity during the period studied. Therefore, we can conclude that there is a lack of productive performance at the global and sectoral level. The results obtained show that the capacity utilization rate is an effective instrument for the analysis of productive efficiency.

\section{Relationship between CU, TFP and Elasticities}

\subsection{Short and Long Run Elasticity Estimates}

At $C R S$, the elasticity of production capacity $\left(\varepsilon_{Y i}\right)$ measured by $\varepsilon_{K i}$ is positively related to the labor price, but negatively related to the energy price. Production capacity shows the greatest sensitivity to the labor price. The negative sign is consistent with some degree of substitutability between capital and energy in the long run. Instead, we find evidence of a significant long-run complementarity between capital and labor. However, the sensitivity of the production capacity, due to the short-run growth of the energy price, is positive but generally low. Berndt and Hesse (1986) noted that the $\varepsilon_{Y E}$ is equal to the negative long run capital elasticity following the changes in the energy price. The increase in energy price tends to reduce the demand for long-run capital.

The elasticity of the production capacity compared to the change in the cost of capital measured by $\varepsilon_{K K}$ is compatible with the results of Berndt and Hesse. The production capacity of $Y^{*}$ is positively related to the growth of the capital cost. This occurs because the price elasticity of capital is negative. Therefore, any increase in the capital cost will decrease the optimal ratio $(K / Y)$ in the long run. Thus, for a given stock of capital, the short-run production capacity should be high.

Table 14. Estimates of short-run elasticities

\begin{tabular}{lllllll|llllllll}
\hline Year & \multicolumn{1}{l}{ Short run } & \multicolumn{1}{l|}{ Long run } \\
\cline { 2 - 12 } & $\varepsilon_{Y L}$ & $\varepsilon_{Y E}$ & $\sigma_{L L}$ & $\sigma_{E E}$ & $\sigma_{L E}$ & $\sigma_{E L}$ & $\varepsilon_{K K}$ & $\varepsilon_{K L}$ & $\varepsilon_{K E}$ & $\varepsilon_{L K}$ & $\varepsilon_{E K}$ & $\varepsilon_{L Y}$ & $\varepsilon_{E Y}$ \\
\hline 1970 & -0.20 & -0.16 & -0.64 & -0.46 & 0.64 & 0.46 & 0.36 & 0.20 & 0.16 & -0.43 & -0.26 & 0.57 & 0.75 \\
1980 & -0.21 & -0.13 & -0.65 & -0.46 & 0.65 & 0.46 & 0.34 & 0.21 & 0.13 & -0.29 & -0.13 & 0.71 & 0.87 \\
1986 & -0.38 & 0.03 & -0.48 & -7.05 & 0.48 & 7.05 & 0.35 & 0.38 & -0.03 & -0.33 & 0.38 & 0.67 & 1.38 \\
1991 & -0.38 & 0.03 & -0.49 & -14.54 & 0.49 & 14.54 & 0.35 & 0.38 & -0.03 & -0.41 & 0.93 & 0.59 & 1.93 \\
2000 & -0.40 & 0.06 & -0.57 & 5.95 & 0.57 & -5.95 & 0.33 & 0.40 & -0.06 & -0.51 & -0.85 & 0.49 & 0.15 \\
2006 & -0.41 & 0.09 & -0.62 & 3.84 & 0.62 & -3.84 & 0.32 & 0.41 & -0.09 & -0.54 & -0.71 & 0.46 & 0.29 \\
\hline
\end{tabular}

It is possible to analyze some points of the $C U$ in terms of change in the price of the exogenous variables. As noted previously, the measure of production capacity is very sensitive to changes in the capital cost and energy price. In general, the production capacity is not too sensitive to the change in the energy price. However, the sensitivity of the production capacity following the changes in the capital user cost is particularly useful for the explanation of the $C U$. The interesting period which needs to be analyzed corresponds to the decline of the $C U$ trend which was observed between 1980 and 1987.

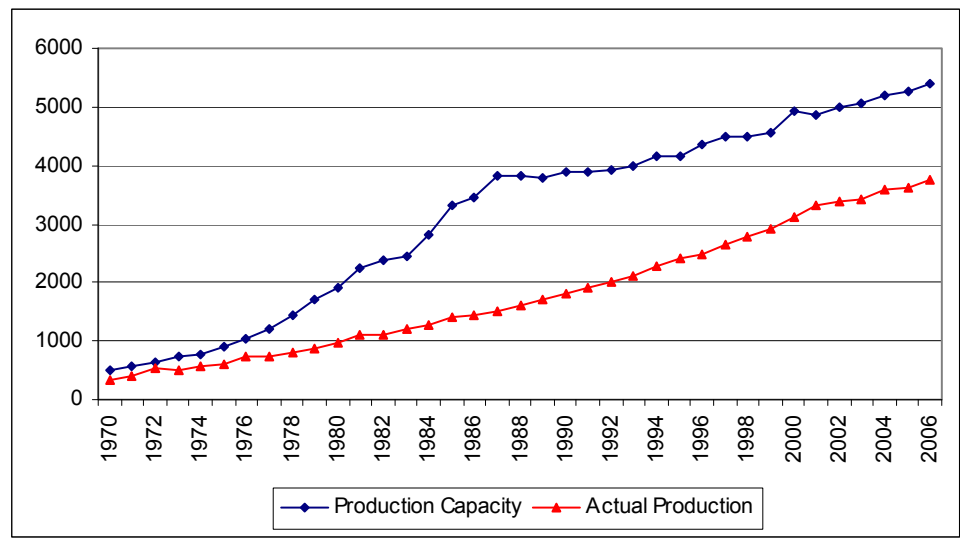

Figure 4. Evolution of the production capacity 
From Figure4, the production capacity increased, on average, at a substantially faster rate than the current production. This period associated with a substantial increase in the capital cost and therefore (logically with positive sign of $\varepsilon_{Y K}$ ) led to a decline in the level of registered $C U$. Conversely, the great rise of the $C U$ in 1998 corresponds to a period where the user cost of capital decreased substantially, that is a decrease in the average productivity of the capital by $47 \%$ between 1988 and 1999. The subsequent decline of the $C U$ between 2000 and 2006 coincides with the period where the capital cost increased significantly because of the return to the accumulation of capital (growth rate of capital in the order of $0.6 \%$ ).

\subsection{Estimates of Total Factor Productivity}

Table 15 summarizes the values of primal and dual TFP estimates from CRSTranslog average variable cost function. Throughout the entire 1970-2006 period, the annual growth in multifactor productivity was measured using three inputs, capital $(K)$, labor $(L)$ and energy $(E)$, indicating an overall annual decrease in the short run of $5 \%$. It is clear that there is a strong correlation between the results of primal and dual measures.

Table 15. Estimates of different TFP at CRS

\begin{tabular}{lllll}
\hline Year & $\varepsilon_{C Y}$ & $\varepsilon_{Y t}$ & $\varepsilon_{Y t}{ }^{L T}=\varepsilon_{C t}{ }^{L T}$ & $\varepsilon_{C t}$ \\
\hline 1971 & 0.570 & 0.184 & 0.194 & 0.111 \\
1980 & 0.345 & 0.112 & 0.106 & 0.037 \\
1986 & 0.218 & 0.023 & 0.009 & 0.002 \\
1991 & 0.227 & 0.035 & 0.029 & 0.006 \\
2000 & 0.294 & 0.056 & 0.041 & 0.012 \\
2006 & 0.379 & 0.031 & 0.023 & 0.009 \\
\hline Minimum & 0.197 & -0.018 & -0.001 & -0.001 \\
Maximum & 0.641 & 0.247 & 0.260 & 0.167 \\
Average & 0.329 & 0.064 & 0.062 & 0.024 \\
Standard Deviation & 0.112 & 0.056 & 0.061 & 0.036 \\
\hline
\end{tabular}

In general, a substantial quantity of productivity decline was evident between 1971 and 1987 . In fact, the objective of such an adjustment for the estimation of productivity is to measure under equilibrium. The empirical significance of this adjustment, which is reported in Table 16 by the annual averaged growth rate of $\varepsilon_{C t}{ }^{L R}$, differs across the periods. Over time, the above results reveal a modest decline in the dispersion of productivity measures with adjustment in the under-equilibrium. In addition, the 70-80 period still appears to be a period of poor productivity performance and, after 1973, it was even more catastrophic because of the large unexpected shocks, especially in the case of a single quasi-fixed input.

However, a big change in productivity appears to have occurred before 1987. Between 1971-1980, the average annual growth rate dropped by $11.5 \%$ and between 1980 and 1987, it fell to $25 \%$. The second measured productivity growth $\varepsilon_{Y t}{ }_{Y R}$ is more dramatic. We observe an average decrease of $6.5 \%$ between 1971-1980 and reached $18.7 \%$ between 80 and 87 . This appears to be a result of the significant decline in productivity, especially in 1987 , by $0.9 \%$. In 1973 , the average annual growth rate was negative. This period could be a strong candidate for the title of productivity growth slowdown. However, this productivity slowdown is due to the oil crisis of that period.

Table 16. Comparison of CU, TFP and elasticities at CRS

\begin{tabular}{lllll}
\hline Periods & $\mathrm{CU}$ & $\varepsilon_{Y t}{ }^{S R}$ & $\varepsilon_{Y t}{ }^{L R}$ & $\varepsilon_{C t}$ \\
\hline $1971-2006$ & -1.20 & -5.00 & -5.90 & -7.00 \\
$1971-1980$ & -5.40 & -5.40 & -6.50 & -11.50 \\
$1980-1987$ & -7.70 & -15.30 & -18.70 & -25.00 \\
$1987-1991$ & 3.60 & 0.30 & 3.50 & 7.20 \\
$1991-2000$ & 3.00 & 5.20 & 4.10 & 7.20 \\
$2000-2006$ & 4.30 & -9.50 & -9.10 & -5.20 \\
\hline
\end{tabular}

From 1987, we notice an improvement of the TFP to a level of the average growth, which reached a maximum of 3.5\%. Between 1991-2000, we observed a low productivity growth accompanied by an increase in the $C U$. Following various economic and geopolitical issues, we return to the lowering of productivity and $C U$ growth. In 
general, during the period 1970-2006, these problems resulted from a total effect rather than a substantial one of the decline in productivity which does not give a conclusive evidence of a unique sudden slowdown of the productivity growth before 1973 or 1987 in the Tunisian industry.

Most of the industrial sectors can be specified where the economy of scale $\left(\varepsilon_{C Y}{ }^{L R}<1\right)$ is installed and the $C U$ is relatively low as $\varepsilon_{C Y}^{S R}<1$ and we will have a small measure of TFP. Due to the fixity of the socio-economic infrastructure, the long-run economies of scale $\left(\varepsilon_{C Y}{ }^{L R}\right)$ are measured along the long run marginal cost curve (LRMC). As previously reported, $\varepsilon_{C Y}$ is the long-run cost elasticity $\varepsilon_{C Y}{ }^{L R}$ which fits the measuring of the dual $C U$. Graphically, this relationship implies that if the $C U<1$, then the slope of the $S R A C$ curve is steeper than the $L R A C$ curve. Hence, $\varepsilon_{C Y}{ }^{L T}>\varepsilon_{C Y}$ where the short-run economies of scale are larger than the long run ones.

\section{Conclusion}

This work focuses on the implications and difficulties of estimating, on the one hand, the production capacity, and on the other hand, the measurement of the total factor productivity from the marginal cost adjustment of the quasi-fixed inputs in the short run, and therefore the need to instantaneously distinguish between the short and long run impacts. In fact, the higher $C U$, the more the economy tends to invest, provided that the demand forecasts are favourable. Therefore, we highlight the effect of the economies of scale on this growth.

In summary, the empirical decomposition of the productivity residue consists in isolating the effect of the technical progress regardless the under-equilibrium, the anticipation behaviour and the economies of scale leading to important conclusions. These include: (i) the anomaly to observe a productivity growth slowdown before 1987 and even between 2000 and 2006 using conventional exaggerated methods; (ii) the fundamental impact produced from a quasi-fixed factor model and with non-static expectations; and (iii) the productivity growth slowdown that probably started as soon as 1987, or even 1973.

\section{References}

Bai, J., \& Ng, S. (2004). A PANIC Attack on Unit Roots and Cointegration. Econometrica, 72(4), 1127-1178. http://dx.doi.org/10.1111/j.1468-0262.2004.00528.x

Berndt, R. E., \& Hesse, D. (1986). Measuring and Assessing capacity utilization in the manufacturing sectors of nine OECD countries. European Economic Review, 30, 961-989. http://dx.doi.org/10.1016/S0014-2921(86)80001-0

Berndt, R. E., \& Morrison, C. J. (1981). Capacity utilization measures: Underlying Economic Theory and an Alternative Approach. American Economic Review, 71, 48-52.

Bhargava, A., Franzini, L., \& Narendranathan, W. (1982). Serial correlation and the fixed effects model. Review of Economic Studies, 49(4), 533-549. http://dx.doi.org/10.2307/2297285

Brown, R. S., \& Christensen, L. (1981). Estimating Elasticity's of Substitution in a model of partial static equilibrium: An application to US agriculture, 1947-1974. In Ernst R. Berndt and Barry C. Fields (Eds.), Modeling and Measuring Natural Resource Substitution (pp. 209-229). Cambridge MA: MIT Press.

Cassels, J. M. (1937). Excess Capacity and Monopolistic Competition. Quarterly Journal of Economics, 51, 426-443. http://dx.doi.org/10.2307/1884835

Chang, Y. (2002). Nonlinear IV Unit Root Tests in Panels with Cross-Sectional Dependency. Journal of Econometrics, 110, 261-292. http://dx.doi.org/10.1016/S0304-4076(02)00095-7

Choi, I. (2002). Combination Unit Root Tests for Cross-Sectionally Correlated Panels. Mimeo, Hong Kong University of Science and Technology.

Christensen, L. R., Jorgensen, D. W., \& Lau, L. J. (1973). Transcendental Logarithmic Production Frontiers. Review of Economics and Statistic, 55(1), 28-45. http://dx.doi.org/10.2307/1927992

Chung, J. (1987). On the Estimation of Factor Substitution in the Translog Model. Review of Economics and Statistics, 64(3), 409-417. http://dx.doi.org/10.2307/1925528

Diewert, W. E., \& Morrison, C. J. (1987). Productivity Growth and Changes in the Terms of Trade in Japan and the U.S. NBER Working Papers 1848, National Bureau of Economic Research, Inc.

Friedman, M. (1963). More on Archibald versus Chicago. Review of Economic Studies, 30, 65-67. 
http://dx.doi.org/10.2307/2296033

Hadri, K. (2000). Testing for Unit Roots in Heterogeneous Panel Data. Econometrics Journal, 3, 148-161. http://dx.doi.org/10.1111/1368-423X.00043

Hickman, B. G. (1964). A New Method of Capacity Estimation. Journal of the American Statistical Association, 59, 529-549. http://dx.doi.org/10.1080/01621459.1964.10482177

Im, K. S., Pesaran, M. H., \& Shin, Y. (2003). Testing for Unit Roots in Heterogeneous Panels. Journal of Econometrics, 115(1), 53-74. http://dx.doi.org/10.1016/S0304-4076(03)00092-7

Kao, C. (1999). Spurious Regression and Residual-Based Tests for Cointegration in Panel Data. Journal of Econometrics, 90, 1-44. http://dx.doi.org/10.1016/S0304-4076(98)00023-2

Klein, L. R. (1960). Some Theoretical Issues in the Measurement of Capacity. Econometrica, 28, 272-286. http://dx.doi.org/10.2307/1907721

Levin, A., Lin, C. F., \& Chu, C. S. J. (2002). Unit Root Test in Panel Data: Asymptotic and Finite Sample Properties. Journal of Econometrics, 108, 1-24. http://dx.doi.org/10.1016/S0304-4076(01)00098-7

Maddala, G. S., \& Wu, S. (1999). A Comparative Study of Unit Root Tests with Panel Data and a New Simple Test. Oxford Bulletin of Economics and Statistics, Special Issue 0305-9049, 631-652. http://dx.doi.org/10.1111/1468-0084.61.s1.13

Moon, H. R., \& Perron, B. (2004). Testing for a Unit Root in Panels with Dynamic Factors. Journal of Econometrics, 122, 81-126. http://dx.doi.org/10.1016/j.jeconom.2003.10.020

Morrison, C. J. (1985). Primal and dual capacity utilisation: an application to productivity measurement in the US automobile industry. Journal of Business and Economic Studies, 3, 312-323.

Pedroni, P. (1999). Critical values for cointegration tests in heterogeneous panels with multiple regressors.Oxford Bulletin of Economics and Statistics, Special Issue, 653-669. http://dx.doi.org/10.1111/1468-0084.61.s1.14

Pesaran, H. M. (2007). A simple panel unit root test in the presence of cross-section dependence. Journal of Applied Econometrics, 22(2), 265-312. http://dx.doi.org/10.1002/jae.951

Segerson, K., \& Squires, D. E. (1990). On the measurement of economic capacity utilization for multi-product industries. Journal of Econometrics, 44, 347-361. http://dx.doi.org/10.1016/0304-4076(90)90063-Y

Somayeh, M. C., Ghasem, T., Shaghayegh, L., \& Sanaz, M. C. (2012). Capacity utilization of buyer-supplier relationships. Indian Journal of Science and Technology, 5(9).

Wegener, D. T., \& Petty, R. E. (1994). Mood management across affective states: The hedonic contingency hypothesis. Journal of Personality and Social Psychology, 66, 1034-1048. http://dx.doi.org/10.1037/0022-3514.66.6.1034

Zellner, A. (1962). An efficient method of estimating seemingly unrelated regression and tests for aggregation bias. Journal of the American Statistical Association, 57(298), 348-68. http://dx.doi.org/10.1080/01621459.1962.10480664

\section{Copyrights}

Copyright for this article is retained by the author(s), with first publication rights granted to the journal.

This is an open-access article distributed under the terms and conditions of the Creative Commons Attribution license (http://creativecommons.org/licenses/by/3.0/). 